This is the final peer-reviewed accepted manuscript of:

G. Rizzoli, M. Mengoni, A. Tani, G. Serra, L. Zarri and D. Casadei, "Wireless Power Transfer Using a Five-Phase Wound-Rotor Induction Machine for Speed-Controlled Rotary Platforms" in IEEE Transactions on Industrial Electronics, vol. 67, no. 8, pp. 6237-6247, Aug. 2020

The final published version is available online at:

https://doi.org/10.1109/TIE.2019.2935988

Rights / License:

The terms and conditions for the reuse of this version of the manuscript are specified in the publishing policy. For all terms of use and more information see the publisher's website.

This item was downloaded from IRIS Università di Bologna (https://cris.unibo.it/)

When citing, please refer to the published version. 


\title{
Wireless Power Transfer Using a Five-Phase Wound-Rotor Induction Machine for Speed-Controlled Rotary Platforms
}

\author{
Gabriele Rizzoli, Michele Mengoni, Angelo Tani, Giovanni Serra, Senior Member, IEEE \\ Luca Zarri, Senior Member, IEEE, and Domenico Casadei, Fellow, IEEE
}

\begin{abstract}
The use of rotary assembly platforms is common in several automation applications, such as in bottle filling and capping systems. One of the problems that designers has to address is how to supply the electric actuators, sensors and process controllers located on the rotating disk of the machine. The traditional solution is to use slip-ring contacts. However, they suffer from aging and thus a scheduled maintenance program is required. In this paper, the motion of the platform and the contact-less energy transfer to the auxiliary loads located on the rotating disk is obtained through a direct drive woundrotor five-phase induction motor. The experimental tests on a scaled prototype demonstrate the practical potential of the machine.
\end{abstract}

Index Terms - Variable speed drives, Induction motors, Inductive power transmission.

\section{INTRODUCTION}

$\mathrm{N}$ owadays mass production of goods is based on highly automated assembly lines. In some cases, to perform bottling and capping tasks, the products are loaded on a rotating disk and driven through sequential machining and assembly stations. Some examples of industrial rotary assembly platforms are shown in Fig. 1. The processes are generally carried out by actuators and tools positioned on the fixed frame of the machine. Therefore, the primary role of the disk is the angular positioning of the products. In complex production lines, however, the disk has not only a passive role. Additional processing can be carried out by actuators located on the rotating platform. In these cases, it is necessary to transfer energy from the fixed frame to the rotating one. The most straightforward and robust approach is to use mechanical actuators powered by cams. This solution is not flexible and becomes impractical in case of advanced machining. A more flexible alternative is to use pneumatic actuators, whose fluid is transferred to the platform through pneumatic or hydraulic rotary joints. However, both solutions

Manuscript received January 30, 2019; revised May 26, 2019, accepted July 26, 2019. This work was supported in part by the European Regional Development Fund under Grant J32I16000070007 (Project "Sinergie", Integrated Solutions for Next-Generation Automated Machines).

G. Rizzoli, M. Mengoni, A. Tani, G. Serra, L. Zarri and D. Casadei are with the Dept. of Electric, Electronic and Information Engineering "G. Marconi", University of Bologna, Bologna, Italy (e-mail: gabriele.rizzoli@unibo.it, michele.mengoni@unio.it, angelo.tani@unibo.it, giovanni.serra@unibo.it, luca.zarri2@unibo.it, domenico.casadei@unibo.it). are inadequate if the production process requires the presence of sensors and electronic control systems on the rotating disk. In this case, the approach usually adopted is to transfer electrical energy and control signals to the rotating platform by using slip rings, consisting of electrical brushes that rub on a conductive ring. This solution is commonly used in several industrial applications; however, the inevitable wear of carbon brushes requires frequent maintenance and preventive replacement to avoid malfunctions that may cause the interruption of the production [1]-[3]. To increase the reliability of the rotary assembly stations, it is possible to remove the slip-rings dedicated to the control signals transmitting the information through wireless communication technologies. However, the problem is only partially solved since all the electronic systems on the rotating platform need to be powered. A viable solution to remove the slip-rings is to transfer electrical energy to the rotating platform by using electromagnetically coupled systems. A variety of proposals can be found in the literature. Most of them consist of inductive or capacitive coupled circuits controlled by power electronics converters [4]-[7]. A less common approach is to use a direct-drive electric machine able to control simultaneously the position of the disk and the electric power transferred to the rotor. In [8], an electric drive based on a three-phase salient pole synchronous machine has been developed. A sinusoidal current is induced in the rotor winding by a high-frequency component of the stator current $i_{S d}$. To keep the torque constant, the authors have developed an ingenious analytical solution to calculate the setpoint of the current $i_{S q}$, which depends on the machine parameters and the rotor load. The residual torque oscillation is due to the limited

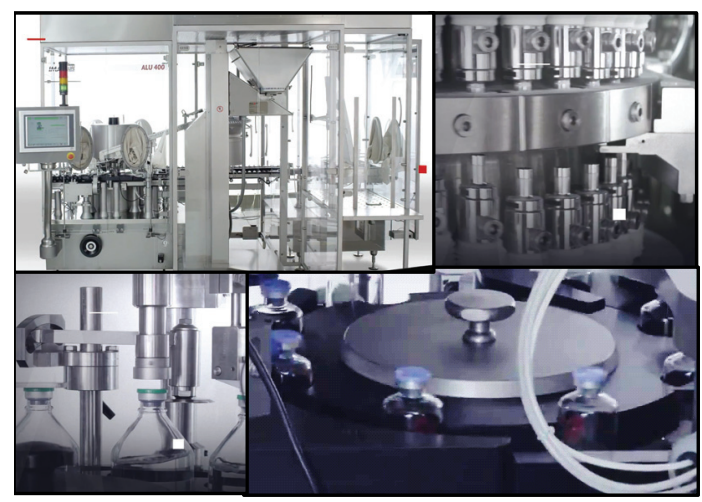

Fig. 1 - Examples of rotary tables used for capping machines and tablet press machines. Photo gently provided by IMA Group. 
bandwidth of the current regulators which do not allow tracking the references perfectly. This machine is essentially an integration of an electric motor and a rotary transformer.

For the independent control of the motor torque and the rotor power, two degrees of freedom are required. A system with these characteristics, for example, can be implemented by means of mixed-pole machines. In this electromagnetic structure, two distinct three-phase windings differing in the pole pairs are located on the stator [9]-[10]. A mixed-pole motor with two stator windings with different pole pairs and a salient rotor with a three-phase winding, which can be used to feed a load with AC voltage, is presented in [10]. The main control variables are the angular frequencies of the stator windings, which can be chosen to simultaneously control the mechanical speed and the rotor power with acceptable efficiency. A different approach to obtain the same result is to use multiphase electric machines as theorized in [11]. Multiphase windings show the capability of generating and controlling more than one harmonic of the magnetic field in the air gap [12]-[15]. This characteristic makes it possible to cancel the unwanted harmonics of the machine torque [16][17], increase the power density [18], and obtain features such as fault tolerance [19], diagnostics [20], and multimotor control [21].

In this paper, a five-phase direct-drive wound-rotor induction machine is used to drive a rotating platform at a controlled speed and to feed the auxiliary rotor loads without using sliding contacts. The fundamental component of the air gap Magnetomotive Force (MMF) distribution is responsible for the driving torque, while the third spatial harmonic of the MMF delivers power to the rotor loads. To reduce the complexity of the system, a control scheme that does not require information sharing between the stationary controllers and those on the rotating platform has been developed. Experimental tests carried out on a small-scale prototype demonstrate that the developed solution is feasible.

\section{DESCRIPTION OF THE SYSTEM}

A gearless five-phase wound-rotor induction machine is used to drive the rotating platform shown in Fig. 2. The absence of the gearbox allows obtaining precise positioning due to higher stiffness of the drive. The stator winding is connected to a five-phase inverter, which is powered by the electrical grid through an $\mathrm{AC} / \mathrm{DC}$ converter. Also, on the platform, a five-phase rotor inverter connected to the fivephase rotor winding extracts electrical energy from the machine and provides power to the rotating electrical loads. Although other configurations of the rotor winding are possible, the one selected in this paper focuses on the use of multiphase motors for automation applications and does produce a ripple-free mechanical torque.

\section{A. Machine Equations}

In general, a machine with five star-connected phases, symmetrically arranged, allows controlling the fundamental and the third spatial harmonic components of the magnetic field in the air-gap. The operation of the machine can be described by the following mathematical model [22]:

$$
\begin{gathered}
\bar{v}_{S 1}=R_{S} \bar{i}_{S 1}+j \omega_{1} \bar{\varphi}_{S 1}+\frac{d \bar{\varphi}_{S 1}}{d t} \\
\bar{v}_{R 1}=R_{R} \bar{i}_{R 1}+j\left(\omega_{1}-\omega_{m}\right) \bar{\varphi}_{R 1}+\frac{d \varphi_{R 1}}{d t} \\
\bar{\varphi}_{S 1}=L_{S 1} \bar{i}_{S 1}+M_{1} \bar{i}_{R 1} \\
\bar{\varphi}_{R 1}=M_{1} \bar{i}_{S 1}+L_{R 1} \bar{i}_{R 1} \\
\bar{v}_{S 3}=R_{S} \bar{i}_{S 3}+j \omega_{3} \bar{\varphi}_{S 3}+\frac{d \varphi_{S 3}}{d t} \\
\bar{v}_{R 3}=R_{R} \bar{i}_{R 3}+j\left(\omega_{3}-3 \omega_{m}\right) \bar{\varphi}_{R 3}+\frac{d \bar{\varphi}_{R 3}}{d t} \\
\bar{\varphi}_{S 3}=L_{S 3} \bar{i}_{S 3}+M_{3} \bar{i}_{R 3} \\
\bar{\varphi}_{R 3}=M_{3} \bar{i}_{S 3}+L_{R 3} \bar{i}_{R 3}
\end{gathered}
$$

where $\bar{i}_{S k}$ and $\bar{i}_{R k}(k=1,3)$ are the multiple space vectors of the stator and rotor currents, $\bar{\varphi}_{S k}$ and $\bar{\varphi}_{R k}(k=1,3)$ are the multiple space vectors of the stator and rotor fluxes, $\omega_{m}$ is the rotor angular speed in electrical radians, and $L_{S k}$, $L_{R k}$ and $M_{k}(k=1,3)$ are the self and mutual inductances. Finally, (1)-(4) and (5)-(8) hold respectively in the reference frames $d_{1}-q_{1}$ and $d_{3}-q_{3}$ with angular frequencies $\omega_{1}$ and $\omega_{3}$ that are chosen as explained in Section II.B and II.C.

Equations (1)-(4) describe the electromagnetic coupling between the stator and rotor windings through the fundamental spatial harmonic of the magnetic field. Similarly, the interaction between stator and rotor through the third-order spatial harmonic is described by (5)-(8). It is worth noting that the resistances $R_{S}$ and $R_{R}$ in (1)-(2) also appear in (5)-(6) because the resistance of the wound circuits does not depend on the specific harmonic sub-space.

The interaction between the magnetic field generated by currents $\bar{i}_{S 1}-\bar{i}_{R 1}$ and $\bar{i}_{S 3}-\bar{i}_{R 3}$ produces an electromagnetic torque that can be decomposed into two contributions:

$$
\begin{gathered}
T=T_{1}+T_{3} \\
T_{1}=\frac{5}{2} p\left(j \bar{\varphi}_{S 1} \cdot \bar{i}_{S 1}\right) \\
T_{3}=\frac{5}{2} p\left(3 j \bar{\varphi}_{S 3} \cdot \bar{i}_{S 3}\right)
\end{gathered}
$$

where $p$ is the number of pairs of poles, and the dot operator "." is the product of the magnitude of the vectors, and the cosine of the angle between them.

The equation of the motion can be written as:

$$
\frac{J}{p} \frac{d \omega_{m}}{d t}=T_{1}+T_{3}-T_{R}
$$

where $J$ is the moment of inertia of the system, and $T_{R}$ is the braking torque applied to the rotor.

Under the assumption of magnetic linearity, the machine behaves as if it were composed of two electrically independent virtual motors, which act on the same motor shaft. This independence is ensured by the fact that the equations of the 


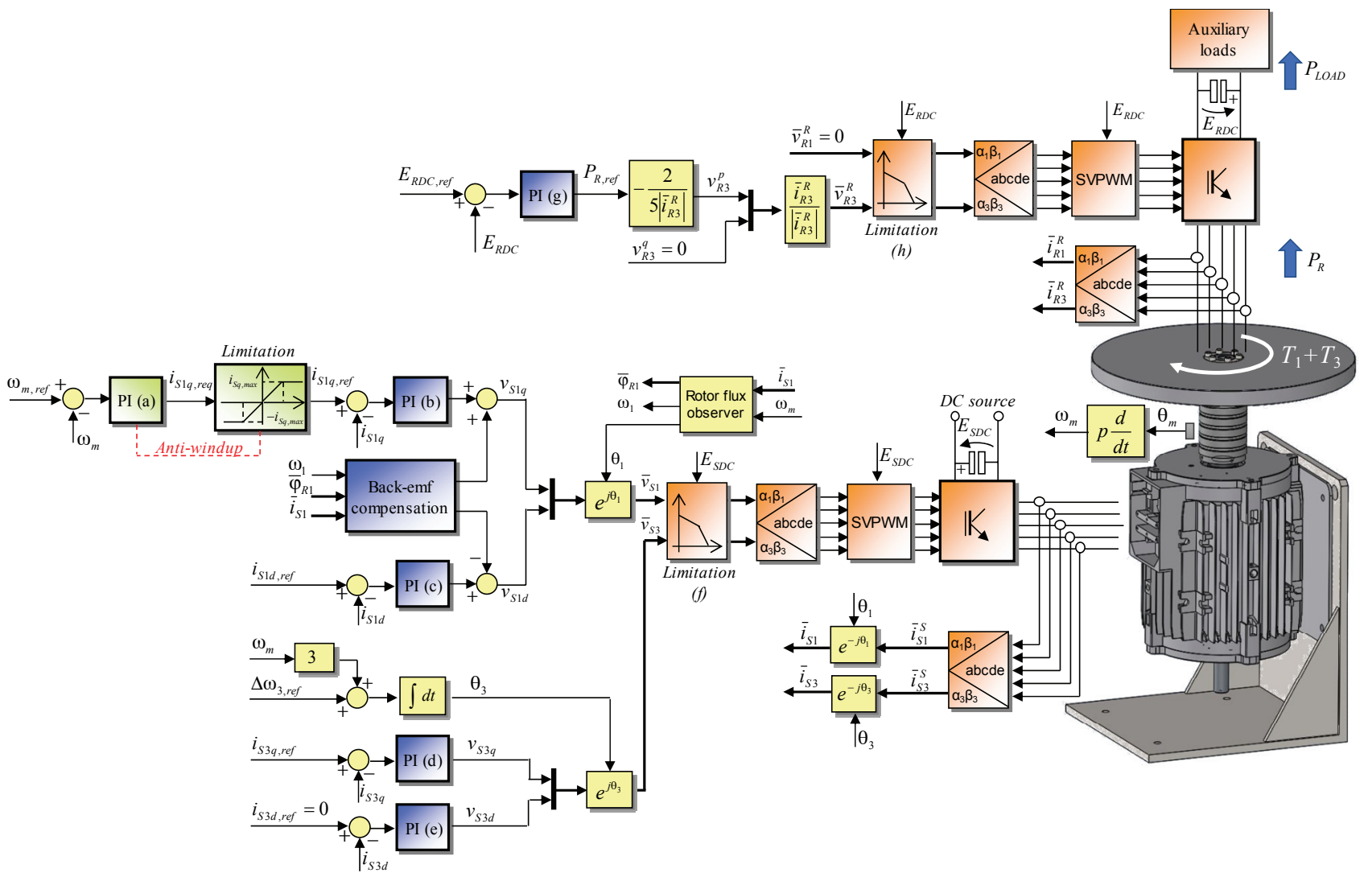

Fig. 2 - Block diagram of the control system and schematics of the five-phase wound-rotor induction motor drive.

virtual motors are written in separated subspaces, and the only shared variable is the mechanical speed of the shaft.

The basic idea of the proposed control scheme is to use the field harmonics of the five-phase machine to control the electromagnetic torque and the electrical energy transferred to the rotor loads. To reduce the complexity of the control system and avoid high-throughput information exchange between the stator and rotor inverters, the fundamental spatial harmonic of the magnetic field is used only for torque generation whereas the third spatial harmonic of the field is used to transfer electric power to the rotating loads.

\section{B. Torque Control}

The fundamental harmonic of the air-gap magnetic field is used to generate the electromagnetic torque and follow the speed profile requested by the industrial processes.

If voltage $\bar{v}_{R 1}$ applied by the rotor inverter is equal to zero, (1)-(4) are equal to the model of a standard three-phase induction machine with short-circuited rotor windings. Therefore, the stator inverter can control torque $T_{l}$ and the rotor flux magnitude $\varphi_{R 1}$ by using a traditional rotor-field oriented control scheme without the measurement of any rotor electrical quantity [23]. In contrast, the task of the rotor inverter is to apply a voltage $\bar{v}_{R 1}$ equal to zero. This operation does not require any feedback information from the control system of the stator.

In a reference frame $d_{1}-q_{1}$ that is aligned with the rotor flux vector $\bar{\varphi}_{R 1}$, combining (2) and (4) under the assumption that $\bar{v}_{R 1}$ is equal to zero leads to the following equation of the rotor flux vector:

$$
\tau_{R 1} \frac{d \varphi_{R 1}}{d t}+\varphi_{R 1}=M_{1} i_{S 1 d}
$$

where $i_{S 1 d}$ is the d-component of the stator current vector $\bar{i}_{S 1}$, and $\tau_{R 1}$ is the rotor time constant $L_{R 1} / R_{R}$.

Equation (10) can be rewritten as a function of the rotor flux magnitude $\varphi_{R 1}$ and the q-component $i_{S 1 q}$ of the stator current vector $\bar{i}_{S 1}$ by means of (3) and (4):

$$
T_{1}=\frac{5}{2} p \frac{M_{1}}{L_{R 1}} \varphi_{R 1} i_{S 1 q} .
$$

Therefore, (13) and (14) show that the $d$ and q components of the stator current can be used to control, respectively, the rotor flux and rotor torque in sub-space $\mathrm{d}_{1}-\mathrm{q}_{1}$.

\section{Generation of a Constant Voltage for Rotor Loads}

The electrostatic energy of the rotor DC-link capacitor $C_{R}$, shown in Fig. 2, depends on the power $P_{R}$ extracted from the rotor windings of the machine by the rotor inverter:

$$
\frac{d}{d t}\left(\frac{1}{2} C_{R} E_{R D C}^{2}\right)=P_{R}-P_{L O A D} .
$$

where $E_{R D C}$ is the voltage of the capacitor $C_{R}$ and $P_{L O A D}$ is the power absorbed by the rotor auxiliary loads.

If $\bar{v}_{R 1}$ is zero, the instantaneous values of the active and reactive powers $P_{R}$ and $Q_{R}$ can be written as:

$$
P_{R}=-\frac{5}{2} \bar{v}_{R 3} \cdot \bar{i}_{R 3}
$$




$$
Q_{R}=-\frac{5}{2} \bar{v}_{R 3} \cdot j \bar{i}_{R 3} .
$$

The control of the power flow can be easily implemented decomposing $\bar{v}_{R 3}$ as the sum of components parallel and orthogonal to the rotor current $\bar{i}_{R 3}$,

$$
\bar{v}_{R 3}=\left(v_{R 3}^{p}+j v_{R 3}^{q}\right) \frac{\bar{i}_{R 3}}{\left|\bar{i}_{R 3}\right|} .
$$

Using (18), (16) and (17) can be rewritten as follows:

$$
\begin{gathered}
P_{R}=-\frac{5}{2} v_{R 3}^{p}\left|\bar{i}_{R 3}\right| \\
Q_{R}=-\frac{5}{2} v_{R 3}^{q}\left|\bar{i}_{R 3}\right| .
\end{gathered}
$$

If the losses of the rotor inverter are neglected, the voltage $v_{R 3}^{p}$ can be used to adjust the voltage of the DC-link capacitor as shown by (15) and (19). The reference value $v_{R 3, \text { ref }}^{p}$ can be calculated by solving (19):

$$
v_{R 3, \text { ref }}^{p}=-\frac{2}{5} \frac{P_{R, r e f}}{\left|\bar{i}_{R 3}\right|} .
$$

To make the requirements of the rotor inverter less demanding, the reactive power $Q_{R}$ can be kept at zero by imposing $v_{R 3, r e f}^{q}=0$. Consequently, the reference voltage $\bar{v}_{R 3, \text { ref }}$ can be obtained combining (18) and (21):

$$
\bar{v}_{R 3, r e f}=-\frac{2}{5} P_{R, r e f} \frac{\bar{i}_{R 3}}{\left|\bar{i}_{R 3}\right|^{2}} .
$$

Equation (22) shows that the control of $P_{R}$ requires the existence of a non-zero rotor current $\bar{i}_{R 3}$. The dynamics behavior of $\bar{i}_{R 3}$ can be understood by analyzing (5)-(8), which are similar to the set of equations of a three-phase woundrotor induction machine with a speed equal to $3 \omega_{m}$. In a reference frame $d_{3}-q_{3}$ rotating at angular speed $\omega_{3}=3 \omega_{m},(6)$ can be rewritten to express the rotor current $\bar{i}_{R 3}$ as follows:

$$
\bar{i}_{R 3}=\frac{1}{R_{R}}\left(\bar{v}_{R 3}-\frac{d \bar{\varphi}_{R 3}}{d t}\right) .
$$

It can be observed that the rotor current can be controlled by a time-varying rotor flux $\bar{\varphi}_{R 3}$. In turn, $\bar{\varphi}_{R 3}$ depends on $\bar{i}_{S 3}$ as can be seen from the expression of $\bar{\varphi}_{R 3}$ in the Laplace domain, found by combining (8) and (23):

$$
\bar{\varphi}_{R 3}=\frac{\tau_{R 3} \bar{v}_{R 3}+M_{3} \bar{i}_{S 3}}{1+s \tau_{R 3}}
$$

where $\tau_{R 3}$ is the rotor time constant $L_{R 3} / R_{R}$.
If the stator control system knew the rotor voltage $\bar{v}_{R 3}$, it could regulate $\bar{\varphi}_{R 3}$ through the stator current vector $\bar{i}_{S 3}$. However, unless a high-speed wireless communication is implemented, the voltage $\bar{v}_{R 3}$ is an unknown quantity for the stator inverter. The full control of the rotor flux, therefore, would require the estimation of the rotor voltage $\bar{v}_{R 3}$, which depends on the instantaneous power requested by rotor electrical loads. A simplified method for controlling the energy transfer, which does not require an exchange of information between rotor and stator inverters, is to excite the rotor flux $\bar{\varphi}_{R 3}$ by injecting a rotating current space vector $\bar{i}_{S 3}$ with constant magnitude and frequency. If the angular frequency $\omega_{3}$ is equal to $3 \omega_{m}+\Delta \omega_{3}$, the angular frequency of the current vector $\bar{i}_{R 3}$ measured by an observer located on the rotor is equal to $\Delta \omega_{3}$, which is a fixed value.

As the frequency $\Delta \omega_{3}$ increases, the derivatives of the flux $\bar{\varphi}_{R 3}$ and the induced current $\bar{i}_{R 3}$ increase, as shown by (23) and (24). Therefore, the power that can be transferred to the rotor increases. This performance improvement occurs at the expense of the iron losses of the machine and the magnitude of the voltage $\left|\bar{v}_{R 3}\right|$ required to sustain the current $\bar{i}_{S 3}$. Therefore, the choice of the frequency $\Delta \omega_{3}$ depends on the maximum power required by the rotor loads.

It is worth noting that the current $\bar{i}_{R 3}$ and the rotor flux $\bar{\varphi}_{R 3}$ depend, in a non-linear way, on the power $P_{R}$ and the amplitude and frequency of the stator current $\bar{i}_{S 3}$. The magnitude of $\bar{i}_{R 3}$ and $\bar{\varphi}_{R 3}$ are free to change. Therefore, the operation of the rotor inverter does not require the knowledge of any electrical variable of the stator.

The interaction between the magnetic fields generated by currents $\bar{i}_{S 3}$ and $\bar{i}_{R 3}$ produces an uncontrolled torque $T_{3}$, but constant at steady state, which can be calculated as:

$$
T_{3}=\frac{5}{2} p \frac{M_{3}}{L_{R 3}}\left(3 j \bar{\varphi}_{R 3} \cdot \bar{i}_{S 3}\right)
$$

The torque component $T_{3}$ can be considered as a disturbance, which should be compensated by the torque $T_{1}$ requested by the speed control loop.

At steady state, if the output power $P_{R}$ transferred to the rotor loads does not change, both $\bar{i}_{S 3}$ and $\bar{\varphi}_{R 3}$ are rotating vectors with angular frequency $\Delta \omega_{3}$ in the rotor reference frame. Therefore, the dot product $j \bar{\varphi}_{R 3} \cdot \bar{i}_{S 3}$ is constant.

In conclusion, while the rotor inverter behaves like an active power rectifier and keeps the rotor DC-link voltage constant, the task of the stator inverter is to inject into the machine a current vector $\bar{i}_{S 3}$ that rotates at speed $3 \omega_{m}+\Delta \omega_{3}$ with respect to a stationary observer. 


\section{CONTROL SYSTEM}

The recent advancements in the control of multiphase drives are illustrated in [24]-[25]. Paper [26] is specific for the control of five phase drives. A control technique is developed through dual-plane vector control, with synchronized fluxes. By vector space decomposition, an analytical model and vector control of the five-phase machine are accomplished in two orthogonal vector planes, d1-q1 and d3-q3. The magnitude and rotating speed of the associated fluxes (fundamental and third harmonic) can be independently controlled in each vector plane. Finally, [27] extends the principles of rotor-field oriented vector control to multiphase machines, in healthy and faulty operation.

The control system of the electric drive developed in this paper is shown in Fig. 2. The vectors with superscript " $S$ " and " $R$ " define quantities respectively in the stator and rotor reference frames $\alpha-\beta$, while the vector quantities without any superscript are defined in rotating reference frames whose positions are identified by $\theta_{1}$ and $\theta_{3}$.

The control system is composed of two independent schemes for the control of the stator inverter and the rotor inverter.

A traditional vector control, implemented in a reference frame with the d-axis aligned with the rotor flux $\bar{\varphi}_{R 1}$, has been implemented to control the main torque contribution, $T_{1}$, which is described by (1)-(4) and (14).

An encoder measures the position of the rotor, and its filtered derivative provides the mechanical speed. The error between the reference speed $\omega_{m, r e f}$ and the measured speed of the motor is compensated by the PI controller (a), which adjusts the setpoint of the current $i_{S I q}$ and, hence, the torque $T_{1}$.

To improve the dynamic performance of the torque control, the value of the reference current $i_{S 1 d \text {,ref }}$ is kept constant so that the magnitude of the rotor flux $\bar{\varphi}_{R 1}$ is equal to $M_{1} i_{S 1 d}$ at steady state.

The current references $i_{\text {SId,ref }}$ and $i_{\text {SIq,ref }}$ are tracked by the PI controllers (b) and (c), which generate the reference voltages $v_{\text {SId,ref }}$ and $v_{\text {Slq,ref }}$. To simplify the tuning of PI (b) and (c), the estimated values of the back-electromotive forces are summed to the output signals.

The rotor flux $\bar{\varphi}_{R 1}$ and its angular speed $\omega_{1}$ can be estimated by means of a flux observer based on (2) and (4), written in a reference frame synchronous to the rotor, and assuming that the voltage $\bar{v}_{R 1}$ is equal to zero.

As described in Section II.C, the third spatial harmonic of the magnetic field in the air gap of the machine is used to transfer electrical energy from the stator to the rotor. The voltage $\bar{v}_{S 3}$ is generated by two PI controllers, (d) and (e), which ensure that the currents $i_{S 3 d}$ and $i_{S 3 q}$ are equal to the references $i_{S 3 d, r e f}$ and $i_{S 3 q, r e f}$. The controllers are implemented in a reference frame $\mathrm{d}_{3}-\mathrm{q}_{3}$ that rotates at an angular speed $\omega_{3}$ equal to:

$$
\omega_{3}=3 \omega_{m}+\Delta \omega_{3}
$$

In this way, the angular frequency of the electromotive forces induced in the rotor windings is constant and equal to $\Delta \omega_{3}$.

Once $\bar{v}_{S 1}$ and $\bar{v}_{S 3}$ are known, the modulating signals of the stator inverter can be synthesized with a technique of pulsewidth modulation [28]. Furthermore, limitation block (f) ensures the operation of the inverter in the linear modulation region.

The variables used by the control scheme of the rotor inverter are expressed in a reference frame synchronous with the rotor, so neither the speed of the rotor nor its position is necessary. As explained in Section II-B, the reference voltage $\bar{v}_{R 1}$ is set to zero to avoid sharing information between the stator and rotor control systems.

The DC-link voltage of the rotor inverter is regulated by a PI controller (g), which adjusts the electrical power $P_{R}$ extracted from the machine. The component $v_{R 3}^{p}$, which is proportional to the active power as shown in (19), is calculated according to (21). Conversely, the component $v_{R 3}^{q}$, which is related to the reactive power extracted from the rotor, is set to zero.

Once $\bar{v}_{R 1}$ and $\bar{v}_{R 3}$ are known, the limitation block (h) ensures the operation of the rotor inverter inside the linear modulation region, while a suitable PWM strategy generates the modulating signals.

Since the control system of the rotor power does not require the knowledge of the machine parameters, it is not affected directly by the inaccuracy of the parameter values. Conversely, the control system of the motor torque is based on rotor-field oriented vector control, which requires the measurement of the rotor position and the knowledge of rotor time constant $\tau_{R 1}$ and mutual inductance $M_{1}$. As a consequence, the steady-state values of the motor speed and the rotor DC link voltage are not particularly affected by a mismatching between the actual values of $\tau_{R 1}$ and $M_{1}$ and these used by the control system because the tracking errors are measured by means of sensors and the closed loop scheme cancels the effect of the disturbances.

\section{EXPERIMENTAL RESULtS}

\section{A. Experimental setup}

An experimental setup has been used to verify the effectiveness of the multiphase electric drive. The picture of a small-scale prototype of a rotary assembly platform is shown in Fig. 3(a). It consists of a five-phase wound-rotor induction motor, two five-phase IGBT inverters, a rotating disk and a resistive load. The motor is a 30 -slots five-phase wound-rotor induction machine with three pairs of poles and distributed windings. Both stator and rotor windings are star-connected with an isolated neutral point.

The rated power of the electric load is $100 \mathrm{~W}$. The speed of $50 \mathrm{rpm}$ is a requirement of the specific industrial application considered in the paper. For example, in bottling systems like those shown in Fig. 1, the nominal speed of the rotating 


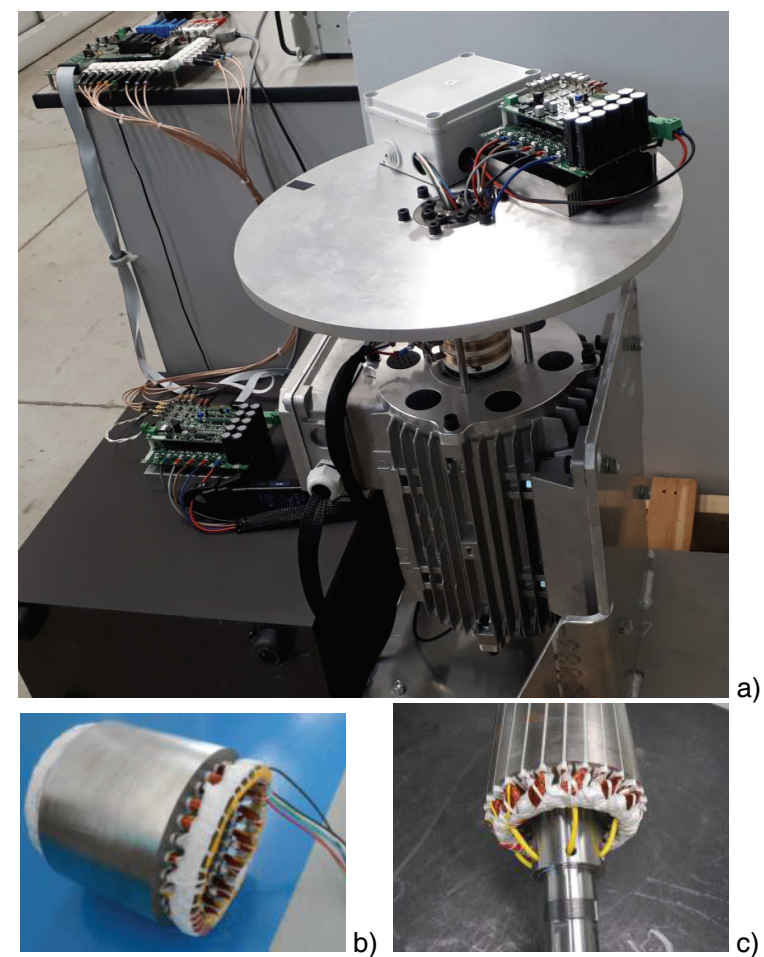

Fig. 3 - Pictures of the experimental setup. a) Small-scale rotary assembly station. b) Details of the stator of the machine. c) Details of the rotor of the machine.

platform is about 1 turn per second.

The system has an electric input port and two output ports, an electrical one and a mechanical one. The rated power of the motor, defined as the sum of $P_{m}$ and $P_{R}$, depends on how the stator current (limited by thermal constraints) is shared between the vector subspaces 1 and 3 . The cross-section of the stator wires is $1.07 \mathrm{~mm}^{2}$ and the winding has been designed for a rated current density of $4 \mathrm{~A}_{\mathrm{RMS}} / \mathrm{mm}^{2}$. The rated stator current $i_{S, R M S \text {, rated }}$ is $4.24 \mathrm{~A}_{\mathrm{RMS}}$.

If the machine produces only mechanical power $\left(\bar{i}_{S 3}=0\right.$ and $\left.P_{R}=0\right)$, the whole current $i_{S, R M S \text {, rated }}$ can be used in subspace 1 for torque generation. With a magnetizing current $i_{S I d}$ of $3.5 \mathrm{~A}$, the rated torque produced by the motor is $43 \mathrm{Nm}$, which corresponds to a mechanical power of $225 \mathrm{~W}$ at 50 rpm. Conversely, the current $i_{S, R M S, \text { rated }}$ has to be shared between $\bar{i}_{S 1}$ and $\bar{i}_{S 3}$ in order to transfer power to the rotor loads without overloading the stator winding. In this paper, $i_{S I d}$ has been set to $3.5 \mathrm{~A}, i_{S 1 q, \max }$ to $3.5 \mathrm{~A}$, and $i_{S 3 q}$ to $3.5 \mathrm{~A}$. This choice keeps the RMS of stator currents at the rated thermal value $i_{S, R M S, \text { rated. }}$. Under these conditions, the mechanical power produced by the motor is reduced by $30 \%$ (nearly $30 \mathrm{Nm}$ at 50 $\mathrm{rpm}$ ), while the maximum power that can be transferred to the rotor is $150 \mathrm{~W}$. Therefore, the ratio between the mechanical power $P_{m}$ and the electric power $P_{R}$ is nearly one.

The parameters of the machine, experimentally determined, are listed in Table I, whereas the physical characteristics of the prototype are shown in Tab.II.

It can be observed that the end-terminals of the rotor winding pass inside a hollow shaft and are connected to a rotor terminal board, mounted on the rotating disk, and to a
TABLE I - PARAMETERS OF THE FIVE-PHASE MACHINE

\begin{tabular}{cc}
\hline$\omega_{\text {m,rated }}=5.2 \mathrm{rad} / \mathrm{s}(50 \mathrm{rpm})$ & $p=3$ \\
$R_{S}=1.7 \Omega$ & $R_{R}=4.8 \Omega$ \\
$L_{S 1}=411 \mathrm{mH}$ & $L_{S 3}=68 \mathrm{mH}$ \\
$L_{R 1}=939 \mathrm{mH}$ & $L_{R 3}=158 \mathrm{mH}$ \\
$M_{1}=555 \mathrm{mH}$ & $M_{3}=53 \mathrm{mH}$ \\
\hline
\end{tabular}

slip-ring system, which has been installed only for laboratory testing.

The values of $T_{1}$ and $T_{3}$ are constant at steady state and the prototype does not produce appreciable torque pulsation. However, torque oscillations may arise due to the interaction between the geometry of the stator and rotor teeth. To suppress the torque perturbation of the prototype, the rotor geometry has skewed slots. The most suitable skew angle for the motor was determined by $3 \mathrm{D}$ finite elements simulations.

Some mechanical details of the stator and rotor of the machine are shown in Fig. 3(b) and (c).

The control scheme shown in Fig. 2 does not require any communication between the stator and rotor inverters. Therefore, the control algorithm has been implemented on two independent control platforms based on TMS320F28335 digital signal controllers by Texas Instruments. The frequency of the PWM modulator during the tests has been set to 10 $\mathrm{kHz}$, whereas the gains of the PI regulators of the control scheme are reported in Table III. The voltage supply of the stator inverter has been kept at $250 \mathrm{~V}$ by a TDK Lambda GEN600-5.5 power supply.

The magnetizing current $i_{S 1 d, \text { ref }}$ of the stator current vector $\bar{i}_{S 1}$ has been kept constant at $3.5 \mathrm{~A}$ during the tests to avoid undesired torque transients. The component $i_{S 1 q, \text { ref }}$ generated by the speed controller has been limited to $\pm 3.5 \mathrm{~A}$, resulting in a maximum torque $T_{1}$ of nearly $30 \mathrm{Nm}$.

The magnitude of the current vector $\bar{i}_{S 3}$ has been set to 3.5 A, while the angular speed $\Delta \omega_{3}$ is $628.3 \mathrm{rad} / \mathrm{s}(100 \mathrm{~Hz})$. The reference voltage for the DC-link capacitor of the rotor inverter is $100 \mathrm{~V}$.

\section{B. Steady state and transient performance}

Fig. 4 shows the components $i_{S 1 \alpha}$ and $i_{S 1 \beta}$ of the current vector $\bar{i}_{S 1}^{S}$, and the components $i_{S 3 \alpha}$ and $i_{S 3 \beta}$ of the current vector $\bar{i}_{S 3}^{S}$ when the setpoint of the speed decreases from 50

\begin{tabular}{lc} 
TABLE II -PHYSICAL DETAILS OF THE FIVE-PHASE MACHINE \\
\hline \hline External diameter of the motor & $240 \mathrm{~mm}$ \\
Active length of the motor & $165 \mathrm{~mm}$ \\
Iron core material & M400-50A \\
Number of pair of poles & 3 \\
Stator slots number & 30 \\
Rotor slots number & 30 \\
Skew angle between stator and rotor & $14^{\circ}$ \\
Number of stator conductors per slot & 58 \\
Number of rotor conductors per slot & 89 \\
\hline
\end{tabular}


TABle III PARAmeters of the Regulators

\begin{tabular}{ll}
\hline \hline Speed regulator (a) & $k_{p}=0.2 \mathrm{~A} \cdot \mathrm{s}, k_{i}=0.4 \mathrm{~A}$ \\
\hline Current regulators (b) and (c) & $k_{p}=118 \Omega, k_{i}=600 \Omega / \mathrm{s}$ \\
\hline Current regulators (d) and (e) & $k_{p}=66 \Omega, k_{i}=2000 \Omega / \mathrm{s}$ \\
\hline Power regulator (f) & $k_{p}=10 \mathrm{~A}, k_{i}=100 \mathrm{~A} / \mathrm{s}$ \\
\hline \hline
\end{tabular}

rpm to $10 \mathrm{rpm}$. The loci of vector $\bar{i}_{S 1}^{S}$ and $\bar{i}_{S 3}^{S}$ are circular trajectories, which are travelled at different angular speeds. Furthermore, the steady-state magnitude of $\bar{i}_{S 1}^{S}$ is almost equal to the magnetizing current $i_{S 1 d, \text { ref. }}$. In fact, the braking torque applied to the rotor shaft is zero.

The start-up of the system is investigated in Fig. 5. All the machine quantities are equal to zero for time $t<t_{0}$. At time $t_{0}$, the setpoint of the mechanical speed is set to $60 \mathrm{rpm}$ and the DC-link capacitor of the rotor inverter is charged up to $100 \mathrm{~V}$. The stator phase current $i_{S a}$ shows the superposition of two sinusoidal contributions at low and high frequency. The former comes from $\bar{i}_{S 1}$, the latter from $\bar{i}_{S 3}$. Similarly, $i_{R a}$ contains two harmonics related to $\bar{i}_{R 1}$ and $\bar{i}_{R 3}$. The figure clearly shows that the system can start-up and follow the setpoints of the rotor speed and of the rotor DC-link voltage.

The behavior of the rotor control scheme is shown in Fig. 6 , which depicts the waveforms of the reference voltage $v_{R 3, \text { ref }}^{p}$, the components $v_{R 3 \alpha}$ and $i_{R 3 \alpha}$, and the voltage $E_{R D C}$. At time $t_{0}$ the power $P_{L O A D}$ absorbed by the rotor load increases from $10 \%$ to $100 \%$ leading to a reduction in the voltage $E_{R D C}$. The control loop of the rotor inverter responds to this variation by increasing the power $P_{R}$ extracted from the rotor windings through an adjustment of the reference voltage

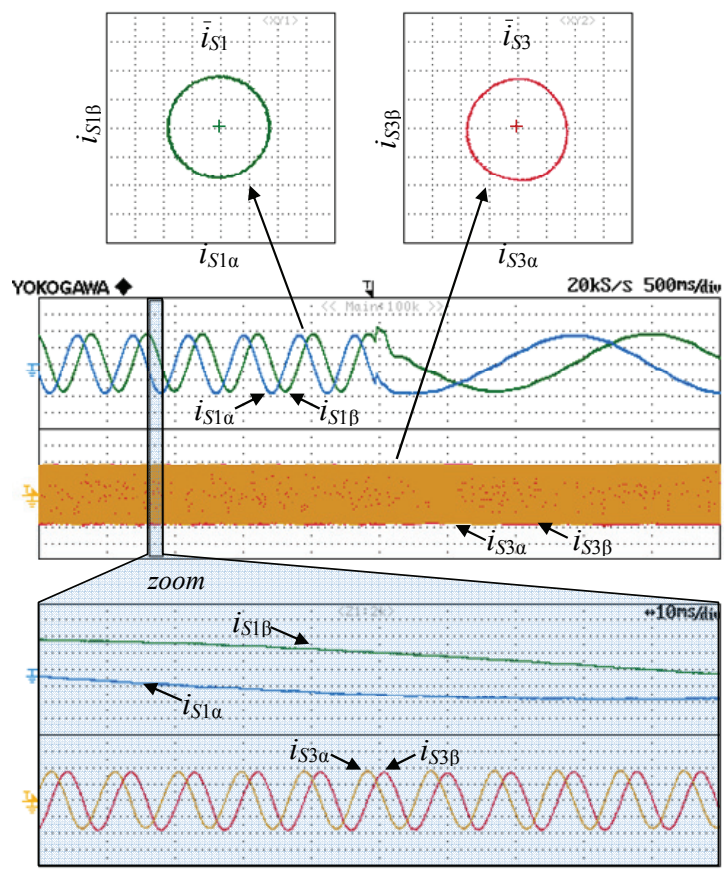

Fig. 4. Components of the current space vectors $\bar{i}_{S 1}^{s}$ and $\bar{i}_{S 3}^{s}$ during a speed variation from $50 \mathrm{rpm}$ to $10 \mathrm{rpm}$. Waveforms of $i_{S 1 \alpha}(2 \mathrm{~A} / \mathrm{div}), i_{S 1 \beta}$ (2 A/div), $i_{S 3 \alpha}(2 \mathrm{~A} / \mathrm{div})$ and $i_{S 3 \beta}(2 \mathrm{~A} / \mathrm{div})$.
$v_{R 3, \text { ref }}^{p}$. It is worth noting that the waveforms of $v_{R 3 \alpha}$ and $i_{R 3 \alpha}$ are in phase opposition, as shown in (22).

Fig. 7 shows the response of the speed control loop of the machine to the variation of the power absorbed by the rotor loads. The figure shows the waveforms of the estimated torque $T_{1}$, the rotor speed $\omega_{\mathrm{m}}$, the voltage $E_{R D C}$, and the power $P_{L O A D}$. During the test, the mechanical speed is $50 \mathrm{rpm}$ and the external braking torque $T_{R}$ applied to the disk is constant and equal to $16 \mathrm{Nm}$. At time $t_{0}$ the power $P_{L O A D}$ increases from 20 $\%$ to $100 \%$. Immediately, the fluctuation of the voltage $E_{R D C}$ is reduced by the rotor inverter. The increase in the power $P_{R}$ leads to a variation of the rotor flux $\bar{\varphi}_{R 3}$ and, thus, of the torque disturbance $T_{3}$, as shown by (22), (24) and (25). Since the braking torque $T_{R}$ in (12) is constant, the speed controller of the machine has to reduce the reference current $i_{S 1 q}$, and hence $T_{1}$, in order to compensate the torque disturbance $T_{3}$. This behavior is clearly presented in Fig. 7. In fact, after $t_{0}$, the torque $T_{1}$ shows a reduction of $\Delta T_{1}$ due to the torque disturbance $T_{3}$. It should be noted that $T_{3}$ has always a positive

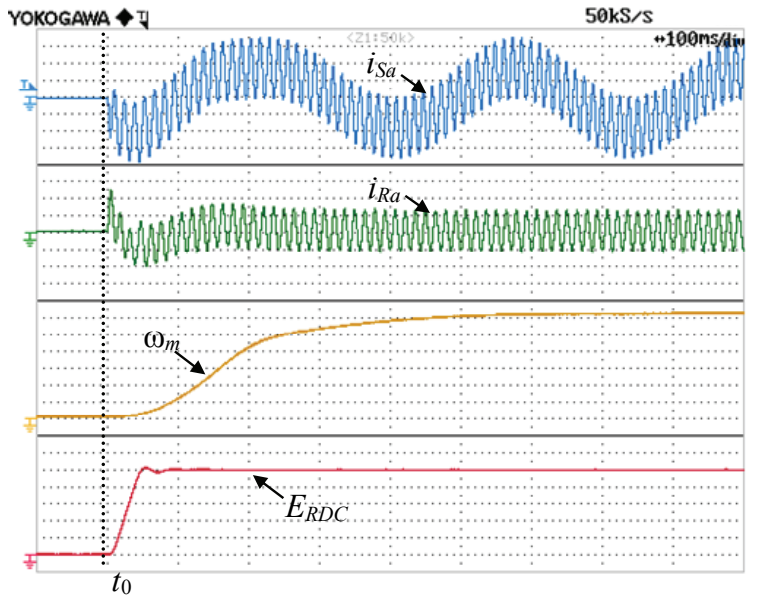

Fig. 5. Start-up behavior of the system with the simultaneous charge of the DC-link capacitor $C_{R}$ and the generation of driving torque. Waveforms of the stator current $i_{s a}(2 \mathrm{~A} / \mathrm{div})$, the rotor current $i_{R a}(1$ $\mathrm{A} / \mathrm{div})$, the mechanical speed $\omega_{\mathrm{m}}(20 \mathrm{rpm} / \mathrm{div})$ and the voltage $E_{R D C}(20$ V/div).

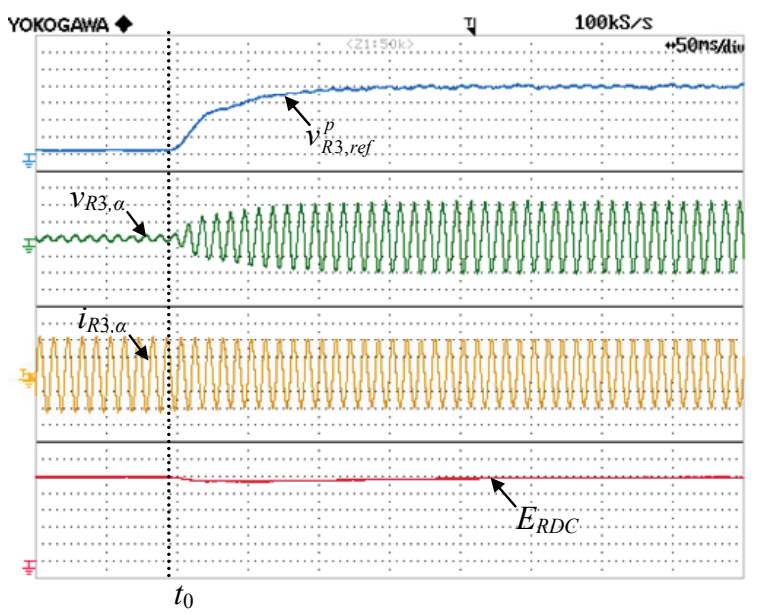

Fig. 6. Response to a step variation of the power absorbed by the rotor loads from $10 \%$ to $100 \%$. Waveforms of the reference voltage $v_{R 3, \text { ref }}^{p}(10 \mathrm{~V} / \mathrm{div})$, the rotor voltage $v_{R 3, \alpha}(20 \mathrm{~V} / \mathrm{div})$, the rotor current $i_{R 3, \alpha}$ $(0.5 \mathrm{~A} / \mathrm{div})$ and the voltage $E_{R D C}(20 \mathrm{~V} / \mathrm{div})$. 
value because the angular frequency $\omega_{3}$ of the stator current $\bar{i}_{S 3}^{S}$ is greater than $3 \omega_{\mathrm{m}}$, as shown in (25).

Fig. 8 shows the response of the drive to a variation of the braking torque while the power delivered the rotor loads is equal to $100 \%$ and the setpoint of the speed is $50 \mathrm{rpm}$. It can be noted that the variation of the toque $T_{1}$ does not affect the regulation of the voltage $E_{D C R}$. Therefore, the proposed control scheme can simultaneously adjust the torque $T_{1}$ and the power transferred to the rotating auxiliary actuators, as requested in industrial rotary assembly platforms.

Finally, Fig. 9 shows a speed reversal of the rotor from $-50 \mathrm{rpm}$ to $50 \mathrm{rpm}$ while the setpoint of the DC-link voltage of the rotor inverter is $100 \mathrm{~V}$. In this condition, the rotor load absorbs the rated power and the external braking torque $T_{R}$ is equal to zero. Fig. 9 shows that, during the inversion of the rotor speed, the torque $T_{1}$ is constant at $30 \mathrm{Nm}$ because current $i_{S 1 q, r e f}$ requested by the speed controller has been limited to 3.5 A. Thus, the experimental results confirm that the developed control scheme can independently regulate the speed of the machine and DC-link voltage of the rotor inverter.

\section{Conversion efficiency}

The definition of efficiency for the developed system is not apparent. The system has an electric input and two outputs, one electrical and one mechanical. Moreover, only the total input power of the machine can be experimentally measured. Therefore, it is not possible to define separate efficiency indexes for the mechanical energy conversion and the electric energy transfer but only an overall efficiency index given by

$$
\eta=\frac{\left(T_{1}+T_{3}\right) \omega_{m}+P_{R}}{\left(T_{1}+T_{3}\right) \omega_{m}+P_{R}+P_{\text {losses }}}
$$

where $P_{\text {losses }}$ are the total Joule, iron and mechanical losses of the motor.

It can be observed that the efficiency of the machine is a function of the three variables $T_{1}, P_{R}$, and $\omega_{m}$ ( $T_{3}$ directly

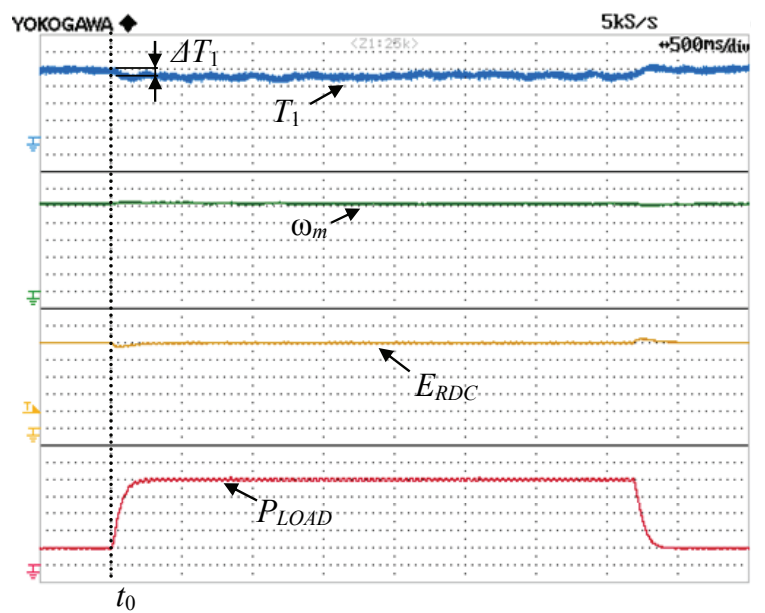

Fig. 7. Response to a variation of the electric power absorbed by the rotor loads from $20 \%$ to $100 \%$, while the setpoint of the speed is 60 $\mathrm{rpm}$ and the braking torque $T_{R}$ is equal to $16 \mathrm{Nm}$. Waveforms of the estimated torque $T_{1}(4 \mathrm{Nm} / \mathrm{div})$, the mechanical speed $\omega_{\mathrm{m}}(10 \mathrm{rpm} / \mathrm{div})$, the voltage $E_{R D C}(20 \mathrm{~V} / \mathrm{div})$, and the power $P_{L O A D}(20 \mathrm{~W} / \mathrm{div})$. depends on $P_{R}$ ). At low mechanical speed, the iron losses and the friction losses of the machine can be neglected, so the overall efficiency of the drive can be easily calculated. Fig. 10 shows the theoretical efficiency of the machine as a function of the mechanical speed $\omega_{m}$ and of the power $P_{R}$ considering $i_{S I d}=3.5 \mathrm{~A}, i_{S I q, \max }=3.5 \mathrm{~A}, i_{S 3 d}=3.5 \mathrm{~A}, \Delta \omega_{3}=628.3 \mathrm{rad} / \mathrm{s}$ and $\mathrm{T}=30 \mathrm{Nm}$.

The experimental efficiency of the machine is about $55 \%$ in rated conditions ( $30 \mathrm{Nm}$ at $50 \mathrm{rpm}$ and $P_{R}=100 \mathrm{~W}$ ). It should be noted that this low efficiency is mainly due to the low speed required by the application. The efficiency of motors that produce the nominal torque at low speed is usually low since the losses are comparable with the nominal ones while the mechanical power is proportional to the speed [29]. The experimental efficiency of the system measured in rated conditions ( $30 \mathrm{Nm}$ at $50 \mathrm{rpm}$ and $P_{R}=100 \mathrm{~W}$ ) is equal to 43 $\%$. This value includes the losses of the five-phase machine and the stator and rotor inverters.

It is worth mentioning that the efficiency of an electrical

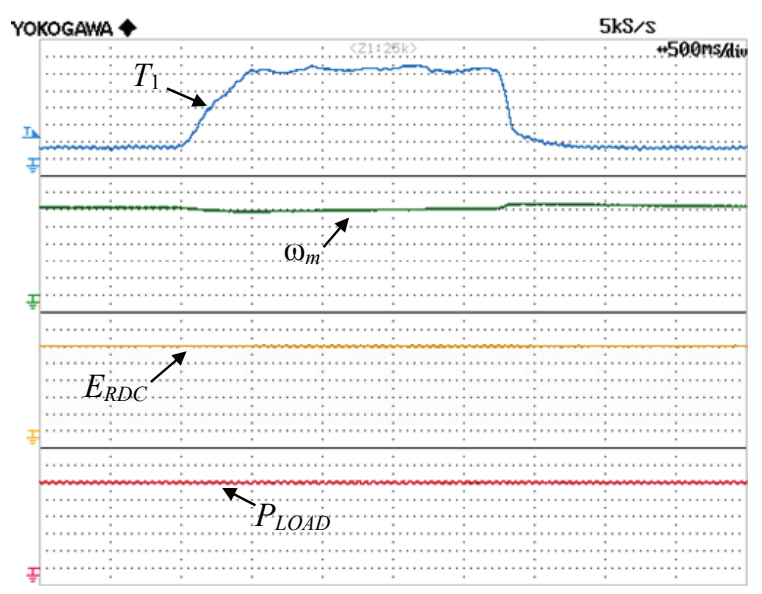

Fig. 8. Behavior of the prototype due to a variation of the braking torque while the setpoint of the speed is $50 \mathrm{rpm}$ and the power transferred to the rotor loads is $100 \%$. Waveforms of the estimated torque $T_{1}$ (5 $\mathrm{Nm} / \mathrm{div})$, the mechanical speed $\omega_{\mathrm{m}}(10 \mathrm{rpm} / \mathrm{div})$, the voltage $E_{R D C}(20$ $\mathrm{V} /$ div), and the power $P_{L O A D}(20 \mathrm{~W} /$ div).

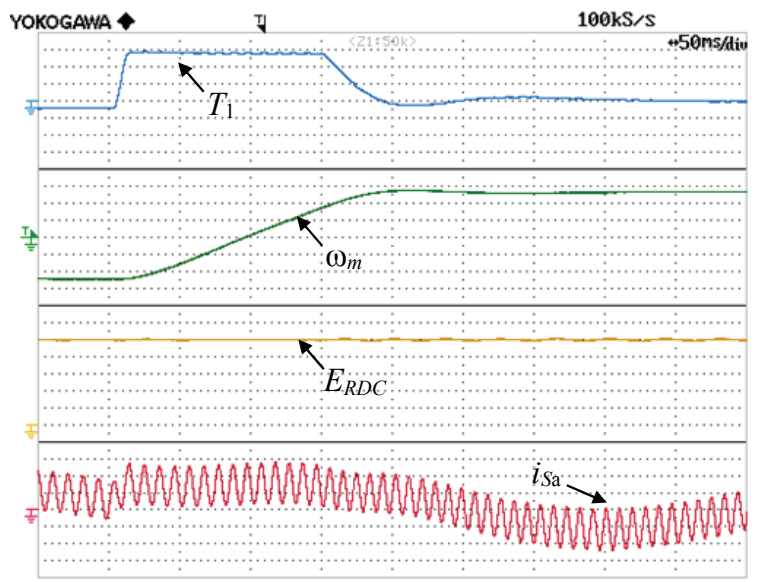

Fig. 9. Speed reversal of the machine from $-50 \mathrm{rpm}$ to $50 \mathrm{rpm}$ while the setpoint of the DC-link voltage of the rotor inverter is equal to $100 \mathrm{~V}$ and the rotor load power is $100 \%$. Waveforms of the estimated torque $T_{1}(10 \mathrm{Nm} / \mathrm{div})$, the mechanical speed $\omega_{\mathrm{m}}(20 \mathrm{rpm} / \mathrm{div})$, the voltage $E_{R D C}(20 \mathrm{~V} / \mathrm{div})$, and the stator current $i_{S a}(3 \mathrm{~A} / \mathrm{div})$. 
machine depends on the design criteria adopted and on the optimization objectives pursued. The prototype is designed by using some traditional criteria for electrical machines, such optimal exploitation of the characteristics of the ferromagnetic material and the conductors. Indeed, a larger volume of the electrical machine would have increased the efficiency of the drive system. In industrial rotary assembly platforms, the rotating disk is usually driven by an induction machine controlled by an inverter and coupled to a mechanical gearbox, while the auxiliary actuators on the rotating platform are powered through slip-rings. Assuming a mechanical power of $150 \mathrm{~W}$, a rated speed of the motor of $750 \mathrm{rpm}$, a motor efficiency of 0.6 , a gearbox efficiency of 0.8 , a power of 100 $\mathrm{W}$ transferred to the rotor loads, a slip-ring system efficiency of 0.9 and an efficiency for the power converters of 0.9 , the overall efficiency of this drive is theoretically equal to $53 \%$, which is not far from that of the small-scale prototype developed in this paper.

\section{CONCLUSION}

Rotating assembly platforms such as bottle filling and capping machines are widely used in automated production chains. On the rotating disk of the platform, the presence of active systems for the supervision of production processes and electric actuators is widespread. The energy required by the auxiliary devices is usually transferred from the fixed frame to the rotating one by slip-ring contacts. However, the brushes are subject to wear, and their ageing can affect the reliability of the automated production chains. This paper shows that a five-phase wound-rotor induction machine can be used to control the motion of the platform and to transfer energy to the loads located on the disk, thus avoiding the use of slip-rings contacts. This result can be achieved through the control of the third-order harmonic component of the air-gap field, which can transfer power to the rotor windings, while the fundamental component of the air-gap field is responsible for the generation of the magnetic torque. The experimental results have confirmed the feasibility of the proposed electric drive topology and the effectiveness of the decoupled control of torque and power.

\section{APPENDIX}

The appendix shows the relationship between the phase variables of a five-phase machine and the corresponding vectors resulting from the vector space decomposition.

For a given set of five real variables $y_{1}, \ldots, y_{k}, \ldots, y_{5}$ a new set of complex variables $\bar{x}_{1}$ and $\bar{x}_{3}$ can be obtained by means of the following symmetrical linear transformation:

$$
\bar{x}_{\rho}=\frac{2}{5} \sum_{k=1}^{5} y_{k} \bar{\alpha}_{k}^{\rho} \quad(\rho=1,3)
$$

where

$$
\bar{\alpha}_{k}=e^{j \frac{2 \pi}{5}(k-1)}
$$

Also, the zero-sequence component is defined as follows:

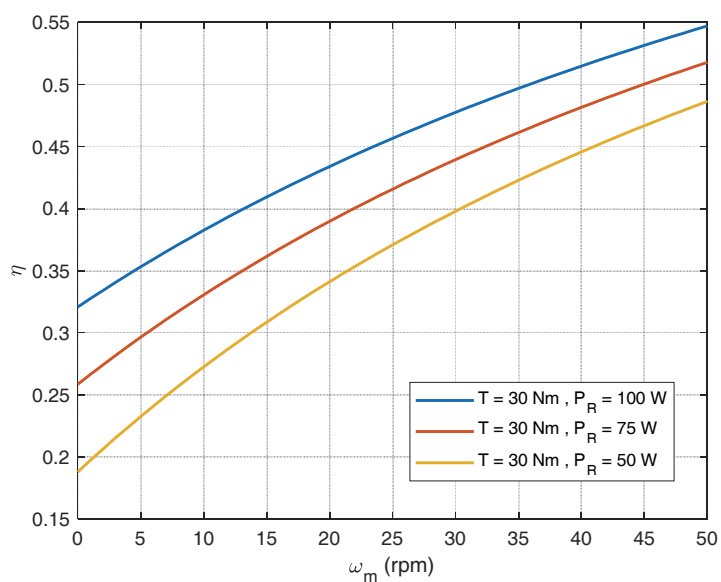

Fig. 10. Theoretical efficiency $\eta$ of the drive as a function of the mechanical speed for different values of the power transferred to the rotor loads.

$$
x_{0}=\frac{1}{5} \sum_{k=1}^{5} y_{k} .
$$

The inverse transformations of (A1) and (A3) are

$$
y_{k}=x_{0}+\bar{x}_{1} \cdot \bar{\alpha}_{k}^{1}+\bar{x}_{3} \cdot \bar{\alpha}_{k}^{3}
$$

where the symbol "." represents the dot product, defined as the real part of the product between the first operand and the complex conjugate of the second.

\section{ACKNOWLEDGMENT}

The authors gratefully acknowledge the support of IMA Group, Ozzano dell'Emilia, Italy, for supporting the project.

\section{REFERENCES}

[1] R. D. Hall and R. P. Roberge, "Carbon brush performance on slip rings," Annual Pulp \& Paper Industry Technical Conference, San Antonio, TX, 2010, pp. 1-6.

[2] J. K. SkjØlberg, H. F. Ohma, and M. Runde, "Wear rates and current distribution of carbon brushes on steel slip rings," IEEE Trans. Energy Convers., vol. 24, no. 4, pp. 835-840, Dec. 2009.

[3] L. Brown, D. Kuhlmann-Wilsdorf, and W. Jesser, "Testing and evaluation of metal fiber brush operation on slip rings and commutators," IEEE Trans. Compon. Packag. Technol., vol. 31, no. 2, pp. 485-494, June 2008.

[4] H. Zhong, L. Zhao and X. Li, "Design and analysis of a three-phase rotary transformer for doubly fed induction generators," IEEE Trans. Ind. Appl., vol. 51, no. 4, pp. 2791-2796, July-Aug. 2015.

[5] X. Zhu, B. Lin, and L. Liu, "Efficiency-based compensations and the mechanical load dependencies of rotary transformer for rotary ultrasonic machining applications," IET Power Electronics, vol. 8, no. 6, pp. 986-993, June 2015.

[6] R. Trevisan and A. Costanzo, "A 1-kW contactless energy transfer system based on a rotary transformer for sealing rollers," IEEE Trans. Ind. Electron., vol. 61, no. 11, pp. 6337-6345, Nov. 2014.

[7] D. C. Ludois, J. K. Reed, and K. Hanson, "Capacitive power transfer for rotor field current in synchronous machines," IEEE Trans. Power Electron., vol. 27, no. 11, pp. 4638-4645, Nov. 2012.

[8] M. I. Masoud, J. E. Fletcher and B. W. Williams, "Decoupled control of rotor torque and rotor electric power delivered in a salient-pole, synchronous machine," IEEE Trans. Energy Convers., vol. 20, no. 1, pp. 45-52, March 2005.

[9] A. R. Munoz and T. A. Lipo, "Dual stator winding induction machine drive," IEEE Trans. Ind. Appl., vol. 36, no. 5, pp. 1369-1379, Sept.-Oct. 2000. 
[10] A. Abdel-Khalik, M. I. Masoud, A. L. Mohamadein, B. W. Williams, and M. Magdy, "Control of rotor torque and rotor electric power of a shaft-mounted electrical load in a mixed pole machine," IET Electric Power Applications, vol. 3, no. 4, pp. 265-278, July 2009.

[11] G. Rizzoli, M. Mengoni, A. Tani, G. Serra, L. Zarri, D. Casadei, "Control of a Direct Drive Five-Phase Wound-Rotor Induction Machine for Rotary Platforms in Automation Applications, " ICEM 2018, September 3-6, 2018, Alexandroupoli, Greece, pp. 1426-1431.

[12] E. Levi, "Advances in converter control and innovative exploitation of additional degrees of freedom for multiphase machines," IEEE Trans. Ind. Electron., Vol. 63, No. 1, pp. 433 - 448, Jan. 2016.

[13] E. Levi, R. Bojoi, F. Profumo, H. A. Toliyat, and S. Williamson, "Multiphase induction motor drives - a technology status review," IET Electric Pow. App., vol. 1, no. 4, pp. 489-516, July 2007.

[14] F. Barrero and M. J. Duran, "Recent advances in the design, modeling, and control of multiphase machines - part I," IEEE Trans. Ind. Electron., vol. 63, no. 1, pp. 449-458, Jan. 2016.

[15] M. J. Duran and F. Barrero, "Recent advances in the design, modeling, and control of multiphase machines - part II," IEEE Trans. Ind. Electron., vol. 63, no. 1, pp. 459-468, Jan. 2016.

[16] S. Williamson and S. Smith, "Pulsating torque and losses in multiphase induction machines," IEEE Trans. Ind. Appl., vol. 39, no. 4, pp. 986993, July-Aug. 2003.

[17] J. M. Apsley, S. Williamson, A. C. Smith, and M. Barnes, "Induction motor performance as a function of phase number," IEEE Proc. Electric Power Applications, vol. 153, no. 6, Nov. 2006.

[18] M. Mengoni, L. Zarri, A. Tani, L. Parsa, G. Serra, and D. Casadei, "High-torque-density control of multiphase induction motor drives operating over a wide speed range," IEEE Trans. Ind. Electron., vol. 62, no. 2, pp. 814-825, Feb. 2015

[19] S. Dwari and L. Parsa, "An Optimal Control Technique for Multiphase PM Machines Under Open-Circuit Faults," IEEE Trans. Ind. Electron., vol. 55, no. 5, pp. 1988-1995, May 2008

[20] F. Immovilli, C. Bianchini, E. Lorenzani, A. Bellini, and E. Fornasiero, "Evaluation of combined reference frame transformation for interturn fault detection in permanent-magnet multiphase machines," IEEE Trans. Ind. Electron., vol. 62, no. 3, pp. 1912-1920, March 2015

[21] E. Levi, M. Jones, S. N. Vukosavic, and H. A. Toliyat, "A novel concept of a multiphase, multimotor vector-controlled drive system supplied from a single voltage source inverter," IEEE Trans. Power Electron., vol. 19, no. 2, pp. 320-335, March 2004.

[22] H. Guzman, M.J. Duran, F. Barrero, L. Zarri, B. Bogado, I. Gonzalez, M. R. Arahal, "Comparative Study of Predictive and Resonant Controllers in Fault-Tolerant Five-Phase Induction Motor Drives," IEEE Trans. Ind. Electron., vol. 63, no. 1, pp. 606-617, Jan. 2016.

[23] L. Zheng, J. E. Fletcher, B. W. Williams, and X. He, "Dual-plane vector control of a five-phase induction machine for an improved flux pattern," IEEE Trans. Ind. Electron., vol. 55, no. 5, pp. 1996-2005, May 2008.

[24] F. Barrero and M. J. Duran, "Recent Advances in the Design, Modeling, and Control of Multiphase Machines - Part I," IEEE Trans. on Ind. Electron., vol. 63, no. 1, pp. 449-458, Jan. 2016.

[25] M. J. Duran and F. Barrero, "Recent Advances in the Design, Modeling, and Control of Multiphase Machines - Part II," IEEE Trans. on Ind. Electron., vol. 63, no. 1, pp. 459-468, Jan. 2016.

[26] L. Zheng, J. E. Fletcher, B. W. Williams and X. He, "Dual-Plane Vector Control of a Five-Phase Induction Machine for an Improved Flux Pattern,” IEEE Trans. on Ind. Electron., vol. 55, no. 5, pp. 1996-2005, May 2008

[27] Z. Liu, Z. Zheng, Q. Wang and Y. Li, "Enhanced rotor field-oriented control of multiphase induction machines based on symmetrical components theory," in IET Power Electronics, vol. 12, no. 4, pp. 656666, April 2019

[28] L. Zarri, M. Mengoni, A. Tani, G. Serra, D. Casadei, "Minimization of the power losses in IGBT multiphase inverters with carrier-based pulsewidth modulation,” IEEE Trans. Ind. Electron., Vol. 57, No. 11, November 2010, pp. 3695 -3706

[29] A. T. De Almeida, F. J. T. E. Ferreira, and J. A. C. Fong, "Standards for Efficiency of Electric Motors," IEEE Industry Applications Magazine, vol. 17, no. 1, pp. 12-19, Jan.-Feb. 2011.

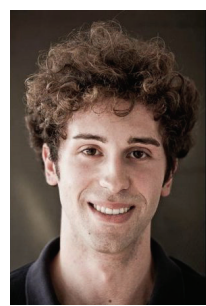

Gabriele Rizzoli received the M.Sc and Ph.D. degree in Electrical Engineering, respectively in 2012 and 2016, from the University of Bologna, Bologna, Italy. In 2015 he was a visiting student at Virginiatech (CPES), Blacksburg, Virginia, United States of America. He is currently a research assistant at the Department of Electrical, Electronic and Information Engineering "G. Marconi" of the University of Bologna. His research interests include the design of electrical machines, the development and control of high-efficient power converters for automotive and renewable energy applications.

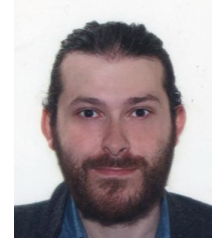

Michele Mengoni was born in Forlì, Italy. He received the M. Sc. and Ph. D. degrees in Electrical Engineering from the University of Bologna, Bologna, Italy, in 2006 and 2010, respectively. He is currently a Senior Assistant Professor with the Department of Electric, Electronic and Information Engineering "G. Marconi", University of Bologna. His research interests include design, analysis, and control of three phase electric machines, multiphase drives, and ac/ac matrix converters.

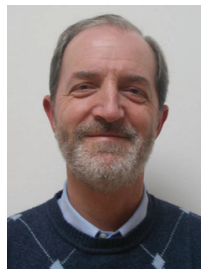

Angelo Tani received the M. Sc. degree in Electrical Engineering, with honors, from the University of Bologna, Bologna, Italy, in 1988. Currently he is a Full Professor of power electronics, electrical machines and drives with the Department of Electric, Electronic and Information Engineering, University of Bologna. He has authored more than 180 papers published in technical journals and conference proceedings. His current activities include multiphase and three phase electric drives, diagnostic techniques for electric machines, and active filters.

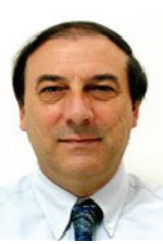

Giovanni Serra (SM'04) received the M. Sc. degree (with honors) in electrical engineering from the University of Bologna, Bologna, Italy, in 1975. Since 2001 has been a Full Professor of Electrical Machines and Electrical Drives with the Department of Electrical, Electronic, and Information Engineering "Guglielmo Marconi". He has authored more than 200 papers published in technical journals and conference proceedings. His research interests include electrical machines, electrical drives, and power electronic converters. He has been an Associate Editor for IEEE Transactions on Industrial Electronics since 2011 and IET-EPA since 2016. Prof. Serra is a member of the IEEE Industrial Electronics Society, IEEE Industry Applications, IEEE Dielectrics and Electrical Insulation Societies.

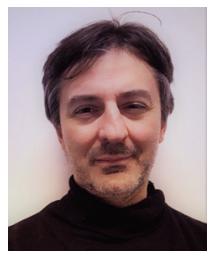

Luca Zarri (M'05-SM'12) received the M. Sc. and Ph.D. degree in Electrical Engineering from the University of Bologna, Bologna, Italy, in 1998 and 2007, respectively. Currently, he is an Associate Professor with the Department of Electrical, Electronic, and Information Engineering "Guglielmo Marconi", University of Bologna. He has authored or coauthored more than 150 scientific papers. His research activity concerns the control of power converters and electric drives. He is a senior member of the IEEE Industry Applications, IEEE Power Electronics and IEEE Industrial Electronics Societies.

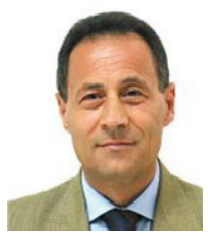

Domenico Casadei (F'15, SM'04) received the M. Sc. in Electrical Engineering (with honors) from the University of Bologna, Italy, in 1974. He is currently Full Professor of Electrical Drives with the Department of Electrical, Electronic, and Information Engineering "Guglielmo Marconi", University of Bologna. He is author and co-author of more than 250 scientific papers, published in technical journals and conference proceedings. His present research areas are vector control of AC drives and diagnosis of electrical machines. He is a member of the IEEE Industrial Electronics Society, IEEE Power Electronics Society and European Power Electronics Society. He has been elevated to the grade of IEEE Fellow for contributions to direct torque control and matrix converters in electric drives. 